\title{
Cardiovascular outcomes during treatment with dabigatran: comprehensive analysis of individual subject data by treatment
}

This article was published in the following Dove Press journal:

Vascular Health and Risk Management

10 October 2013

Number of times this article has been viewed

\author{
Andreas Clemens' \\ Mandy Fraessdorf ${ }^{2}$ \\ Jeffrey Friedman ${ }^{3}$ \\ 'Corporate Division Medicine, \\ TA Cardiovascular, ${ }^{2}$ Medical Data \\ Services, Boehringer Ingelheim \\ $\mathrm{GmbH} \& \mathrm{Co} K G$, Ingelheim am Rhein, \\ Germany; ${ }^{3}$ Boehringer Ingelheim \\ Pharmaceuticals Inc, Ridgefield, \\ CT, USA
}

Background: Dabigatran $150 \mathrm{mg}$ twice daily was shown to be superior to warfarin in preventing stroke in subjects with nonvalvular atrial fibrillation (SPAF) in the RE-LY (Randomized Evaluation of Long-term anticoagulation therapY) trial. Numerically, more myocardial infarctions occurred in patients receiving dabigatran compared with well-controlled warfarin. This observation prompted a comprehensive analysis of cardiovascular outcomes, including myocardial infarction, in all completed Phase II and III trials of dabigatran etexilate.

Methods: The analysis included comparisons of dabigatran with warfarin, enoxaparin, and placebo. Data were analyzed for the occurrence of cardiovascular events from 14 comparative trials $(n=42,484)$ in five different indications. Individual study data were evaluated, as well as pooled subject-level data grouped by comparator.

Results: In the pooled analysis of individual patient data comparing dabigatran with warfarin (SPAF and venous thromboembolism treatment indications), myocardial infarction occurrence favored warfarin (odds ratio [OR] 1.30, 95\% confidence interval [CI] 0.96-1.76 for dabigatran $110 \mathrm{mg}$ twice daily and OR $1.42,95 \%$ CI $1.07-1.88$ for dabigatran $150 \mathrm{mg}$ twice daily). The clinically relevant composite endpoint of myocardial infarction, total stroke, and vascular death demonstrated numerically fewer events in dabigatran $150 \mathrm{mg}$ patients (OR $0.87,95 \% \mathrm{CI}$ 0.77-1.00), but was similar for dabigatran $110 \mathrm{mg}$ (OR 0.99, 95\% CI 0.87-1.13). Dabigatran had similar myocardial infarction rates when compared with enoxaparin or placebo.

Conclusion: These analyses suggest a more protective effect of well-controlled warfarin, but not enoxaparin, compared with dabigatran in preventing myocardial infarction in multiple clinical settings. Dabigatran showed an overall positive benefit-risk ratio for multiple clinically important cardiovascular composite endpoints in all evaluated clinical indications. In conclusion, these data suggest that myocardial infarction is not an adverse drug reaction associated with use of dabigatran.

Keywords: cardiovascular events, stroke, myocardial infarction, dabigatran etexilate, warfarin, atrial fibrillation

\section{Introduction}

Thrombotic cardiovascular disease remains a major public health challenge. Dabigatran etexilate (hereafter referred to as dabigatran) is a direct, reversible thrombin inhibitor that provides a potential alternative to long-established and newer oral and parenteral anticoagulants for the treatment and prevention of various thromboembolic diseases. In the RE-LY (Randomized Evaluation of Long-term anticoagulation therapY) atrial fibrillation study, dabigatran etexilate $150 \mathrm{mg}$ twice daily was associated with significantly lower rates of the primary efficacy composite endpoint of stroke and systemic embolic events, compared with well-controlled warfarin, with similar rates
Correspondence: Andreas Clemens Boehringer Ingelheim Pharma

GmbH \& Co KG, Bingerstrasse 173 ,

55216 Ingelheim am Rhein, Germany

$\mathrm{Tel}+4961327790606$

Fax +4961327290606

Email andreas.clemens@boehringer-

ingelheim.com 
dabigatran database, and since database searches did not identify any published Phase II or III dabigatran studies other than those known to Boehringer Ingelheim, these comprise all known studies as of January 2012. We prespecified a meta-analytic approach pooling the patient-level data from the clinical trials grouped by treatment, to make comparative assessments of the frequency of MI, cardiovascular, and other vascular outcome events, both as individual events and as components of prespecified composite cardiovascular endpoints, due to the known large differences in the risk of cardiovascular outcomes in the different patient populations studied. For the pooled analyses, we focused on the doses of dabigatran and their respective comparators, as approved by numerous health authorities and recommended in multiple clinical and practice guidance documents.

\section{Materials and methods Subjects and study selection}

The analysis was performed by employees of the market authorization holder of dabigatran etexilate (Boehringer Ingelheim) which resulted in unrestricted access to all patient-level data. Studies included in the analysis were all available Phase II and Phase III trials conducted during the development of dabigatran etexilate that were completed through January 2012. An additional literature search in PubMed, Scopus, and the Web of Science in January 2012 for randomized controlled trials evaluating the safety and efficacy of dabigatran that reported on MI or acute coronary syndrome (ACS) as secondary outcomes, using the search terms "dabigatran" or "dabigatran etexilate" or "BIBR 1048 " and "randomized clinical trial" or "randomized trial" or "randomized controlled trial", did not identify further studies. Finally, the analysis was performed on data from four Phase II $(n=4,478)$ and ten Phase III $(n=38,006)$ studies, all of which included exactly one of the following comparators: warfarin, enoxaparin, or placebo. A brief overview of these trials is given in Table 2. ${ }^{1,2,20-32}$ The studies were conducted between November 2002 and June 2011. Results from all but one of these studies were previously published $^{1,2,20-26,30,32}$ or reported in abstract form; ; $^{28,29,31}$ and one set of data remains unpublished. ${ }^{27}$ As stated earlier, data from two Phase II trials were excluded from these data analyses because they had no active or placebo comparator arm. ${ }^{33,34}$ The follow-up periods in these 14 studies were between 1 month and 5 years. A summary of the individual studies, including the number of subjects treated, treatment outcomes, and primary safety and/or efficacy endpoints, is provided in Table 3.
Table 2 Overview of dabigatran trials included in analysis

\begin{tabular}{|c|c|}
\hline Indication and trials & Comparator; other notes \\
\hline Primary VTE prevention $(n=6)$ & $\begin{array}{l}\text { Enoxaparin }(n=5) \text {; } \\
\text { placebo }(n=1)\end{array}$ \\
\hline BISTRO $\|^{20}$ & $\begin{array}{l}\text { Enoxaparin; no approved } \\
\text { dabigatran dose for this } \\
\text { indication was tested }\end{array}$ \\
\hline Japanese $T K R^{24}$ & Placebo; no CV events occurred \\
\hline RE-MODEL ${ }^{21}$ & Enoxaparin \\
\hline RE-NOVATE ${ }^{22}$ & Enoxaparin \\
\hline RE-MOBILIZE ${ }^{23}$ & Enoxaparin \\
\hline RE-NOVATE $\|^{25}$ & Enoxaparin \\
\hline \multicolumn{2}{|l|}{ Stroke prophylaxis in $\mathrm{AF}(\mathrm{n}=3)$} \\
\hline PETRO ${ }^{26}$ & $\begin{array}{l}\text { Adjusted-dose warfarin; } \\
\text { no CV events occurred }\end{array}$ \\
\hline Japanese $A F^{27}$ & $\begin{array}{l}\text { Adjusted-dose warfarin; } \\
\text { no CV events occurred }\end{array}$ \\
\hline RE-LY',2 & Adjusted-dose warfarin \\
\hline \multicolumn{2}{|l|}{ Secondary VTE prevention $(n=2)$} \\
\hline RE-MEDY 28 & Adjusted-dose warfarin \\
\hline RE-SONATE ${ }^{29}$ & Placebo \\
\hline \multicolumn{2}{|l|}{ Acute VTE treatment $(n=2)$} \\
\hline RE-COVER ${ }^{30}$ & Adjusted-dose warfarin \\
\hline RE-COVER $\|^{31}$ & Adjusted-dose warfarin \\
\hline \multicolumn{2}{|l|}{$\operatorname{ACS}(n=1)$} \\
\hline RE-DEEM ${ }^{32}$ & Placebo \\
\hline
\end{tabular}

Abbreviations: AF, atrial fibrillation; $\mathrm{ACS}$, acute coronary syndrome; $\mathrm{CV}$, cardiovascular; VTE, venous thromboembolism; TKR, total knee replacement; BISTRO, Boehringer Ingelheim Study in Thrombosis; PETRO, Dabigatran with or without concomitant aspirin compared with warfarin alone in patients with nonvalvular atrial fibrillation; RE-DEEM, RandomizEd Dabigatran Etexilate Dose Finding Study in Patients With Acute Coronary Syndromes Post Index Event With Additional Risk Factors for Cardiovascular Complications Also Receiving Aspirin and Clopidogrel: Multi-centre, Prospective, Placebo Controlled, Cohort Dose Escalation Study; RE-LY, Randomized Evaluation of Long-term anticoagulation therapY; RE-COVER, A Randomized Trial of Dabigatran Versus Warfarin in the Treatment of Acute Venous Thromboembolism; RE-MODEL, Regulation of Coagulation in Orthopedic surgery to pRevent Deep venous thrombosis and pulmonary embolism; RE-NOVATE, Oral dabigatran versus enoxaparin for thromboprophylaxis after primary total hip arthroplasty; RE-MOBILIZE, prevention of venous thromboembolism after total knee arthroplasty trial; RE-MEDY, A Phase III, Randomised, Multicenter, Double-blind, Parallel-group, Active Controlled Study to Evaluate the Efficacy and Safety of Oral Dabigatran Etexilate (150 mg bid) Compared to Warfarin (INR 2.0-3.0) for the Secondary Prevention of Venous Thromboembolism; RE-SONATE, Twice-daily Oral Direct Thrombin Inhibitor Dabigatran Etexilate in the Long Term Prevention of Recurrent Symptomatic VTE.

As expected, the trial populations differed in terms of demographic and baseline characteristics (eg, age and concomitant disease therapy), the prevalence of known coronary disease, active or placebo comparators, and trial durations (Supplementary Table 1). Dabigatran was administered once daily in seven trials and twice daily in ten trials, some of which also had once-daily arms, and some patients received both once-daily and twice-daily doses in one trial. All studies were conducted with the approval of local ethics committees and the relevant governmental health authorities, and followed the most stringent of the relevant guidelines for the protection of human subjects. Trial registration numbers are listed in Table 3. 
Table 3 Summary of studies included in the meta-analyses

\begin{tabular}{|c|c|c|c|c|c|c|c|c|}
\hline Study & $\begin{array}{l}\text { Trial registration } \\
\text { numbers }\end{array}$ & $\begin{array}{l}\text { Total treated } \\
\text { (number on } \\
\text { dabigatran) }\end{array}$ & $\begin{array}{l}\text { Dose } \\
(\mathrm{mg})\end{array}$ & Duration & Comparator & Best data & $\begin{array}{l}\text { Events } \\
\text { adjudicated }\end{array}$ & $\begin{array}{l}\text { Washout } \\
\text { period } \\
\text { (days) }\end{array}$ \\
\hline \multicolumn{9}{|c|}{ Primary VTE prevention in orthopedic surgery } \\
\hline BISTRO $\|^{20}$ & NCT0I225822, 1160.19 & $1,949(1,557)$ & $\begin{array}{l}50,150,225 \text { bid, } \\
300 \text { qd }\end{array}$ & $6-10$ days & Enoxaparin & $\mathrm{AE}$ & None & 7 \\
\hline RE-MODEL 21 & NCT00I68805, 1160.25 & $2,596(1,728)$ & $150,220 \mathrm{qd}$ & $6-10$ days & Enoxaparin & $A C S^{b}$ & MI & 3 \\
\hline RE-NOVATE 22 & NCT00I688I8, II60.48 & $3,463(2,309)$ & $150,220 \mathrm{qd}$ & $28-35$ days & Enoxaparin & $\mathrm{ACS}^{\mathrm{b}}$ & MI & 3 \\
\hline RE-MOBILIZE ${ }^{23}$ & NCT00I5297I, II 60.24 & $2,076(1,382)$ & $150,220 \mathrm{qd}$ & $12-15$ days & Enoxaparin & $\mathrm{ACS}^{\mathrm{b}}$ & MI & 3 \\
\hline Japanese $T K R^{24}$ & NCT00246025, II 60.50 & $512(388)$ & $110,150,220 \mathrm{qd}$ & II-14 days & Placebo & $\mathrm{AE}$ & None & 3 \\
\hline RE-NOVATE $\|^{25}$ & NCT00657I50, II 60.64 & $2,013(1,010)$ & $220 \mathrm{qd}$ & $28-35$ days & Enoxaparin & $\mathrm{AE}$ & None & 3 \\
\hline \multicolumn{9}{|c|}{ Stroke prevention in AF } \\
\hline PETRO ${ }^{26}$ & NCT0I227629, 1160.20 & $502(432)$ & $50,150,300 \mathrm{bid}^{\mathrm{a}}$ & 12 weeks & Warfarin & OUTC & None & 6 \\
\hline Japanese $\mathrm{AF}^{27}$ & NCT0II 36408, II 60.49 & $166(104)$ & II0, 150 bid & 12 weeks & Warfarin & OUTC & None & 6 \\
\hline RE-LY',2 & NCT00262600, II 60.26 & $18,040(12,042)$ & 110,150 bid & 2 years & Warfarin & TIMEV & $\begin{array}{l}\text { MI, CVA, } \\
\text { CVD, VD }\end{array}$ & 6 \\
\hline \multicolumn{9}{|c|}{ Secondary VTE prevention } \\
\hline RE-MEDY 28 & NСT00329238, II 60.47 & $2,856(I, 430)$ & 150 bid & 6-36 months & Warfarin & $\mathrm{ACS}^{\mathrm{c}}$ & MI, CVD & 6 \\
\hline RE-SONATE ${ }^{29}$ & NCT00558259, II 60.63 & $1,343(684)$ & 150 bid & 6 months & Placebo & $\mathrm{ACS}^{\mathrm{c}}$ & $\mathrm{MI}, \mathrm{CVD}, \mathrm{VD}$ & 6 \\
\hline \multicolumn{9}{|c|}{ Acute VTE treatment } \\
\hline RE-COVER ${ }^{30}$ & NCT0029I330, II 60.53 & $2,539(1,273)$ & 150 bid & 6 months & Warfarin & $\mathrm{ACS}^{\mathrm{c}}$ & MI & 6 \\
\hline RE-COVER III & NCT00680I86, II 60.46 & $2,568(1,280)$ & 150 bid & 6 months & Warfarin & $\mathrm{ACS}^{\mathrm{c}}$ & MI & 6 \\
\hline \multicolumn{9}{|l|}{ ACS } \\
\hline RE-DEEM ${ }^{32}$ & NCT00621855, II 60.67 & $\mathrm{I}, 86 \mathrm{I}(\mathrm{I}, 490)$ & $\begin{array}{l}50,75,110 \\
150 \text { bid }\end{array}$ & 6 months & Placebo & TIMEV & MI, CVD & 6 \\
\hline
\end{tabular}

Notes: For best data of ACS and TIMEV, the event-adjudicated column shows the specific event endpoints that were analyzed for a specific study. ${ }^{a}$ Alone or combined with 81 or $325 \mathrm{mg}$ of aspirin; bACS captured by use of MedDRA triggers; 'ACS events captured by investigator evaluation for ACS.

Abbreviations: ACS, MedDRA terms triggering blinded adjudication; AE, adverse event data; AF, atrial fibrillation; bid, twice daily; CVA, stroke; CVD, cardiovascular death; MI, myocardial infarction; qd, once daily; OUTC, outcome event, prespecified and investigator reported, but not adjudicated; TKR, total knee replacement; MedDRA, Medical Dictionary for Regulatory Authorities; TIMEV, time to an outcome event with blinded adjudication; VD, vascular death; VTE, venous thromboembolism; BISTRO, Boehringer Ingelheim Study in Thrombosis; PETRO, Dabigatran with or without concomitant aspirin compared with warfarin alone in patients with nonvalvular atrial fibrillation; RE-DEEM, RandomizEd Dabigatran Etexilate Dose Finding Study in Patients With Acute Coronary Syndromes Post Index Event With Additional Risk Factors for Cardiovascular Complications Also Receiving Aspirin and Clopidogrel: Multicentre, Prospective, Placebo Controlled, Cohort Dose Escalation Study; RE-LY, Randomized Evaluation of Long-term anticoagulation therapY; RE-COVER, A Randomized Trial of Dabigatran Versus Warfarin in the Treatment of Acute Venous Thromboembolism; REMODEL, Regulation of Coagulation in Orthopedic surgery to pRevent Deep venous thrombosis and pulmonary embolism; RE-NOVATE, Oral dabigatran versus enoxaparin for thromboprophylaxis after primary total hip arthroplasty; RE-MOBILIZE, prevention of venous thromboembolism after total knee arthroplasty trial; RE-MEDY, A Phase III, Randomised, Multicenter, Double-blind, Parallel-group, Active Controlled Study to Evaluate the Efficacy and Safety of Oral Dabigatran Etexilate (I50 mg Bid) Compared to Warfarin (INR 2.0-3.0) for the Secondary Prevention of Venous Thromboembolism; RE-SONATE, Twice-daily Oral Direct Thrombin Inhibitor Dabigatran Etexilate in the Long Term Prevention of Recurrent Symptomatic VTE.

\section{Outcomes and definitions}

For the current analyses, the outcomes of interest were MI (including silent MI), stroke, vascular and cardiovascular death, and three prespecified composite outcomes: MI and cardiovascular death; MI and nonfatal stroke; and MI, stroke, and vascular death.

The definitions of an MI event for RE-LY have been previously reported, ${ }^{12}$ and are more inclusive than those included in the Phase III protocols for the apixaban and rivaroxaban atrial fibrillation studies. ${ }^{10,11}$ The definitions of MI for the trials included in these analyses can be found in Supplementary Table 2 .

For all pooled analyses, the best available individual subject data were used to evaluate cardiovascular events, including MI. For studies with independent adjudication of events, positively adjudicated outcome events were considered to be the best available data. If a study did not have a formal cardiovascular event adjudication, then all investigator-reported adverse events, ie, any of the cardiovascular outcome events included in these analyses, were considered outcome events, irrespective of the investigator or company assigned causal relatedness to study treatment. Adverse event selection was based on Medical Dictionary for Regulatory Authorities (MedDRA) preferred terms that were documented in the clinical trial database.

\section{Statistical analyses}

One of the 14 studies did not include a currently approved dose of dabigatran, ${ }^{20}$ and no cardiovascular outcome events were reported in three studies ${ }^{24,26,27}$ (Table 2). The pooled safety analyses included only subjects who had received at least one dose of study drug (because the focus was a safety analysis) and the observation period was from the date of randomization to the date of study termination, to be consistent with intention-to-treat principles. Pooling was based on individual patient data, but "study" was retained as a factor in the statistical models. 
For the pooled analyses, a fixed-effects model based on the Mantel-Haenszel method was used for combining results from individual trials. Because this was planned as a safety analysis, we used the fixed-effects model, which we knew would result in smaller confidence intervals (CIs) than a random-effects model, and as such, between-group differences would be more likely to be considered statistically significant than if a "less conservative" approach using a random-effects model was utilized. However, a randomeffects model was also employed and no substantial differences in the CIs compared with the fixed-effects model were noted (data not shown).

Odds ratios (ORs) (with a 0.5 continuity correction) and 95\% CIs were calculated. A two-sided $P$-value of $<0.05$ was considered to be statistically significant. There was no correction for the multiplicity of comparisons. Heterogeneity was assessed using the Chi-square test. A $P$-value of $<0.10$ was chosen to denote heterogeneity. All analyses were performed using SAS version 9.2 software (SAS Institute Inc, Cary, NC, USA).

\section{Results}

As expected, the patient populations of the 14 identified trials differed in terms of demographic and baseline characteristics (eg, age and concomitant medication use), prevalence of known coronary disease, comparators (active or placebo), and trial duration. Dabigatran was administered once daily in seven trials and twice daily in ten trials, some of which also had once-daily arms, and some patients received both once-daily and twice-daily doses in one trial. These differences were addressed by analyzing the data from studies grouped by different comparators, which also simultaneously addressed the issue of different trial durations (eg, primary VTE prevention in the orthopedic setting for up to 34 days, stroke prevention in atrial fibrillation RE-LY for a mean of 2 years). Nevertheless, the outcome data were consistent when reviewed as results of individual studies or as pooled analyses of individual patient data from studies grouped by comparator.

\section{Comparisons with well-controlled warfarin (trials in subjects with nonvalvular atrial fibrillation and undergoing acute treatment or secondary prevention of VTE)} Pooled analyses of individual subject data versus warfarin

Within the six clinical trials comparing dabigatran $150 \mathrm{mg}$ twice daily versus warfarin, all had a target INR of 2.0-3.0 (Table 2). ${ }^{1,2,26-28,30,31}$ No cardiovascular events were reported in two studies, so the pooled analysis of individual data is derived from data from four trials. . $, 2,28,30,31^{2}$ The occurrence of all stroke (OR 0.68; 95\% CI 0.54-0.85) and nonfatal stroke (OR $0.65 ; 95 \%$ CI $0.49-0.86$ ) favored dabigatran (Figure 1A).

There was a trend to less risk for vascular death in subjects receiving dabigatran $150 \mathrm{mg}$ twice daily compared with warfarin (OR 0.86; 95\% CI 0.73-1.01), occurrence of the composite endpoint of MI, nonfatal stroke, and cardiovascular death (OR 0.91; 95\% CI 0.79-1.06), and the composite endpoint of MI, all stroke, and vascular death (OR 0.87; 95\% CI 0.77-1.00). The OR for the composite outcome of MI and cardiovascular death, comparing dabigatran $150 \mathrm{mg}$ twice daily versus warfarin, measured an OR of 1.06 (95\% CI 0.89-1.26). For MI events alone, there was an elevated rate compared with warfarin, with an OR of $1.42(95 \% \mathrm{CI}$ $1.07-1.88$, Figure 1A). There was no evidence of statistical heterogeneity. Analyses using different treatment intervals showed similar results.

The comparison of individual patient data for dabigatran $110 \mathrm{mg}$ twice daily and warfarin (Figure 1B) included only one trial (RE-LY), ${ }^{1,2}$ because there were no reported cardiovascular events in the only other study that included this dose and warfarin. ${ }^{27}$ Therefore, these data were identical to those reported in Table 4 for the RE-LY trial results. For MI alone, the data favored warfarin (OR 1.30; 95\% CI 0.96-1.76).

Subjects with nonvalvular atrial fibrillation: individual trial data versus well-controlled warfarin

Data are available from the RE-LY trial. As previously reported, ${ }^{1,12}$ annualized rates of stroke occurrence measured $1.44 \%, 1.01 \%$, and $1.58 \%$ per year for dabigatran $110 \mathrm{mg}$ twice daily, dabigatran $150 \mathrm{mg}$ twice daily, and warfarin, respectively, while there was a small, statistically nonsignificant excess occurrence of MI in dabigatran-treated subjects (Table 4). The rates of MI in RE-LY measured 0.82\%, $0.81 \%$, and $0.64 \%$ per year for the dabigatran $110 \mathrm{mg}$ twice daily, dabigatran $150 \mathrm{mg}$ twice daily, and warfarin treatment groups, respectively; the differences did not reach statistical significance. ${ }^{1,12}$ The rates of fatal MI events were all similar and low $(0.13 \%, 0.11 \%$, and $0.10 \%$ per year for dabigatran $110 \mathrm{mg}$, dabigatran $150 \mathrm{mg}$, and warfarin groups, respectively). Of all the RE-LY subjects who sustained an MI, more than half had a history of coronary artery disease and about one third had a history of prior MI. A subgroup analysis showed that while MI occurred more frequently in subjects with a baseline history of coronary artery disease 
A

\section{Source}

MI (including silent)

Stroke

Vascular death

CV death

MI (including silent), CV death

Nonfatal stroke

$\mathrm{MI}$ (including silent), nonfatal stroke, CV death

MI (including silent), stroke, vascular death

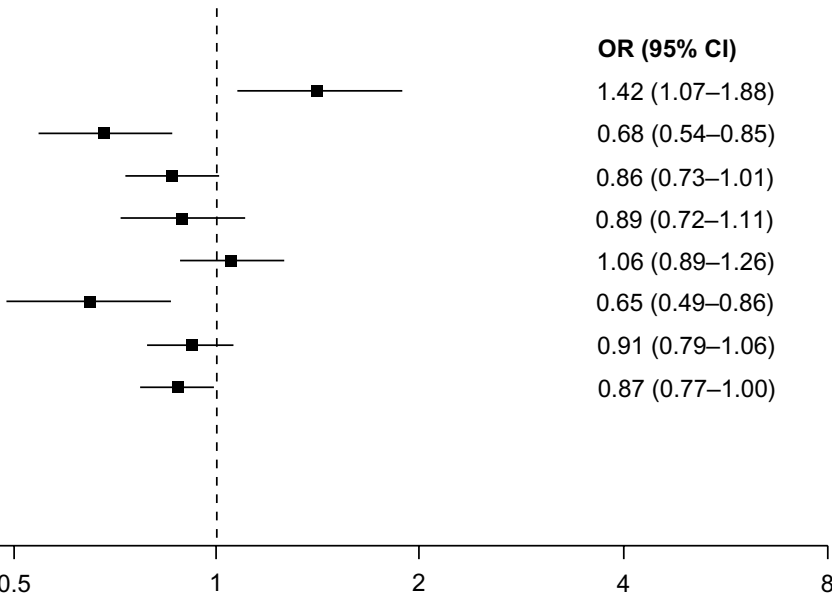

Favors warfarin
OR $(95 \% \mathrm{Cl})$

$0.68(0.54-0.85)$

$0.86(0.73-1.01)$

$0.89(0.72-1.11)$

$0.91(0.79-1.06)$

$.87(0.77-1.00)$

B

\section{Source}

MI (including silent)

Stroke

Vascular death

CV death

MI (including silent), CV death

Nonfatal stroke

$\mathrm{MI}$ (including silent), nonfatal stroke, CV death

MI (including silent), stroke, vascular death

Favors dabigatran

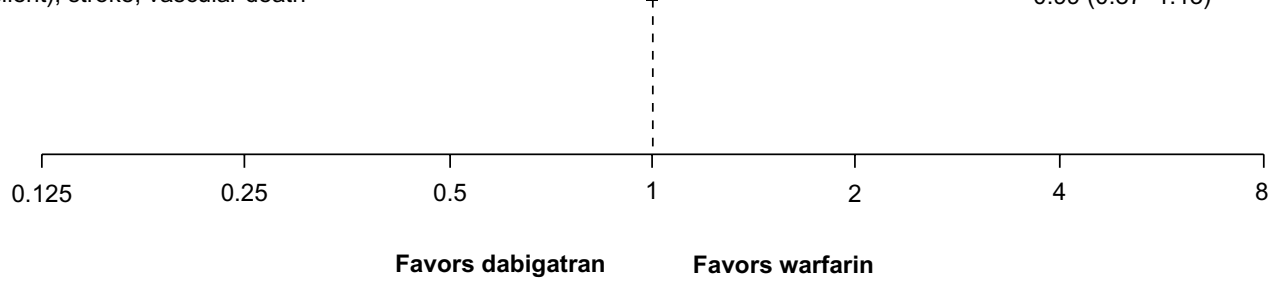

Figure I (A) Cardiovascular events for dabigatran $150 \mathrm{mg}$ twice daily ( $\mathrm{n}=10,042)$ versus warfarin $(\mathrm{n}=9,987)$ in treated patients (randomization to study termination), (B) cardiovascular events for dabigatran $110 \mathrm{mg}$ twice daily $(n=5,983)$ versus warfarin $(n=5,998)$ in treated patients (randomization to study termination). (A) The analysis includes RE-LY, RE-MEDY, RE-COVER, and RE-COVER II. 1,2,28,30,31 Two studies also compared dabigatran I50 mg twice daily versus warfarin, but no cardiovascular events occurred in these studies and they are not included in this comparison. ${ }^{26,27}$ Heterogeneity was seen in the following composite endpoints: MI and stroke not leading to vascular death and cardiovascular death, $P=0.07$; $\mathrm{Ml}$ and stroke and vascular death, $P=0.05$. (B) This analysis includes RE-LY.,2 One study also compared dabigatran II 0 mg twice daily versus warfarin, but there were no cardiovascular events in that study. ${ }^{27}$

Notes: MI (including silent) = clinical MI and silent MI as determined by electrocardiogram changes from baseline; nonfatal stroke = stroke + not vascular death; cardiovascular death = nonfatal $\mathrm{MI}+$ nonfatal stroke + cardiovascular death.

Abbreviations: bid, twice daily; Cl, confidence interval; CV, cardiovascular; MI, myocardial infarction; OR, odds ratio; RE-LY, Randomized Evaluation of Long-term anticoagulation therapY; RE-COVER, A Randomized Trial of Dabigatran Versus Warfarin in the Treatment of Acute Venous Thromboembolism; RE-MODEL, Regulation of Coagulation in Orthopedic surgery to pRevent Deep venous thrombosis and pulmonary embolism; RE-MEDY, A Phase III, Randomised, Multicenter, Double-blind, Parallel-group, Active Controlled Study to Evaluate the Efficacy and Safety of Oral Dabigatran Etexilate (I50 mg Bid) Compared to Warfarin (INR 2.0-3.0) for the Secondary Prevention of Venous Thromboembolism.

versus those without in all treatment groups (Table 4), the MI rates were similar in the dabigatran-treated and warfarintreated subjects for total MI, as well as for subcategories of silent, clinical, and fatal MI. Additionally, when evaluating the effect of INR control in RE-LY, it was noted that those with a mean TTR $\leq 65 \%$ had about a $30 \%$ lower annualized MI rate than warfarin-treated individuals with worse INR control (TTR $<65 \%$, Table 5).
In a post hoc multivariate analysis, the only subgroup to show a statistically significant increase in MI rates with dabigatran versus warfarin was those patients with a baseline history of valvular heart disease $(n=3,955 ; 21.8 \%$ of RE-LY subjects had valvular heart disease without a prosthetic valve or that was not hemodynamically significant or likely to require valve surgery during the conduct of the trial). The identification of such subjects did not require quantification 
Table 4 Rates of MI and CV events in RE-LY, ${ }^{1,2,12}$ randomized set

\begin{tabular}{|c|c|c|c|c|c|c|c|}
\hline & \multirow{2}{*}{$\begin{array}{l}\text { Dabigatran } \\
\text { I I0 mg bid } \\
(\mathrm{n}=6,0 \mid 5) \\
\mathrm{n}(\%)\end{array}$} & \multirow{2}{*}{$\begin{array}{l}\text { Dabigatran } \\
\text { I } 50 \mathrm{mg} \text { bid } \\
(\mathrm{n}=6,076) \\
\mathrm{n}(\%)\end{array}$} & \multirow{2}{*}{$\begin{array}{l}\text { Warfarin } \\
(n=6,022) \\
n(\%)\end{array}$} & \multicolumn{2}{|c|}{$\begin{array}{l}\text { Dabigatran I I } 0 \mathrm{mg} \text { bid } \\
\text { versus warfarin } \\
(\mathrm{n}=\mid 2,037)\end{array}$} & \multicolumn{2}{|c|}{$\begin{array}{l}\text { Dabigatran } 150 \mathrm{mg} \text { bid } \\
\text { versus warfarin } \\
(\mathrm{n}=\mid 2,098)\end{array}$} \\
\hline & & & & RR (95\% Cl) & $P$-value & HR (95\% Cl) & $P$-value \\
\hline All stroke & $171(1.44)$ & $122(1.01)$ & $186(1.58)$ & $0.91(0.74-1.12)$ & 0.38 & $0.64(0.5 \mathrm{I}-0.8 \mathrm{I})$ & $<0.001$ \\
\hline Total MI & $98(0.82)$ & $97(0.8 \mathrm{I})$ & $75(0.64)$ & $1.29(0.96-1.75)$ & 0.09 & $1.27(0.94-|.7|)$ & 0.12 \\
\hline Clinical MI & $87(0.73)$ & $89(0.74)$ & $66(0.56)$ & $1.30(0.95-1.80)$ & 0.10 & $1.32(0.96-1.18)$ & 0.09 \\
\hline Silent MI & II (0.09) & $8(0.07)$ & $9(0.08)$ & $1.22(0.55-2.93)$ & 0.66 & $0.87(0.34-2.27)$ & 0.72 \\
\hline Fatal $\mathrm{Ml}^{\mathrm{a}}$ & $16(0.13)$ & $13(0.11)$ & $12(0.10)$ & $1.32(0.63-2.80)$ & 0.46 & $1.06(0.49-2.33)$ & 0.88 \\
\hline Vascular death & $289(2.43)$ & $274(2.28)$ & $317(2.69)$ & $0.90(0.77-1.06)$ & 0.21 & $0.85(0.72-0.99)$ & 0.04 \\
\hline $\mathrm{CV}$ death $^{\mathrm{b}}$ & I 77 (I.49) & I6I (1.34) & I $74(1.48)$ & I.0I (0.82-1.24) & 0.94 & $0.91(0.73-1.12)$ & 0.37 \\
\hline All-cause mortality & $446(3.75)$ & $438(3.64)$ & $487(4.13)$ & $0.91(0.80-1.03)$ & 0.13 & $0.88(0.77-1.00)$ & 0.05 \\
\hline Clinical MI and CV death & $243(2.04)$ & $235(1.95)$ & $228(1.93)$ & $1.06(0.88-1.27)$ & 0.55 & $\mathrm{I} .0 \mathrm{I}(0.84-\mid .2 \mathrm{I})$ & 0.91 \\
\hline Clinical MI and all-cause death & $505(4.24)$ & $498(4.14)$ & $532(4.5 I)$ & $0.94(0.83-1.06)$ & 0.31 & $0.92(0.81-1.04)$ & 0.16 \\
\hline $\begin{array}{l}\text { Stroke, SEE, PE, all MI, } \\
\text { and vascular death }\end{array}$ & $507(4.26)$ & $443(3.68)$ & $513(4.35)$ & $0.98(0.87-\mathrm{I} . \mathrm{II})$ & 0.75 & $0.84(0.74-0.96)$ & 0.009 \\
\hline \multicolumn{8}{|c|}{ Clinical MI by baseline history of CAD } \\
\hline No & $40(0.5)$ & $42(0.5)$ & $29(0.3)$ & $1.36(0.84-2.20)$ & 0.21 & $\mathrm{I} .43(0.89-2.30)$ & 0.14 \\
\hline Yes & $47(\mathrm{l} .4)$ & $47(\mathrm{l} .4)$ & $37(1.1)$ & $1.27(0.82-1.95)$ & 0.28 & $1.22(0.79-1.87)$ & 0.37 \\
\hline \multicolumn{8}{|c|}{ Clinical MI by baseline history of MI } \\
\hline No & $60(0.6)$ & $52(0.5)$ & $38(0.4)$ & $1.57(1.04-2.36)$ & 0.03 & $1.35(0.89-2.05)$ & 0.16 \\
\hline Yes & $27(1.4)$ & $37(1.8)$ & $28(1.5)$ & $0.94(0.55-1.59)$ & 0.80 & $1.25(0.77-2.05)$ & 0.37 \\
\hline \multicolumn{8}{|c|}{ Clinical MI by baseline history of VHD } \\
\hline No & $60(0.64)$ & $60(0.64)$ & $58(0.63)$ & $\mathrm{I} .02(0.7 \mathrm{I}-\mathrm{I} .46)$ & 0.93 & I.02 (0.7I-I.46) & 0.93 \\
\hline Yes & $27(1.06)$ & $29(1.08)$ & $8(0.3 \mathrm{I})$ & $3.44(1.57-7.58)$ & 0.002 & 3.5 I (1.60-7.67) & 0.002 \\
\hline
\end{tabular}

Notes: aWithin 30 days of event; 'sudden and nonsudden cardiac death. Part of this table is adapted from The New England Journal of Medicine, Connolly SJ, Ezekowitz MD, Yusuf S, Reilly PA, Wallentin L, Newly identified events in the RE-LY trial, 363(19):1875-1876.I Copyright (C) 20I0 Massachusetts Medical Society. Reprinted with permission from Massachusetts Medical Society. Part of this table is adapted with permission from Lippincott Williams and Wilkins/Wolters Kluwer Health: Circulation. Hohnloser SH, Oldgren J, Yang S, et al, Myocardial ischemic events in patients with atrial fibrillation treated with dabigatran or warfarin in the RE-LY (Randomized Evaluation of Long-Term Anticoagulation Therapy) trial. 2012;125(5):669-676.12 Copyright (c) 2012.

Abbreviations: bid, twice daily; CAD, coronary artery disease; Cl, confidence interval; CV, cardiovascular; HR, hazard ratio; MI, myocardial infarction; PE, pulmonary embolism; RR, relative ratio; SEE, systemic embolic event; VHD, valvular heart disease; RE-LY, Randomized Evaluation of Long-term anticoagulation therapY.

of valvular disease severity (eg, with ultrasound) but was based on investigator-reported medical history only. The MI rates in this group measured $1.06 \%, 1.08 \%$, and $0.31 \%$ per year for dabigatran $110 \mathrm{mg}$ twice daily, dabigatran $150 \mathrm{mg}$ twice daily, and warfarin, respectively (Table 4). In subjects without valvular heart disease, the MI rates were $0.64 \%$, $0.64 \%$, and $0.63 \%$ per year for the three treatment groups, respectively (Table 4), showing no difference between those receiving dabigatran and warfarin. The MI rate in the warfarin group with a baseline history of valvular heart disease was low, with very few events having been diagnosed $(n=8)$, and the rate was about half the MI rate $(0.31 \%$ per year $)$ observed in warfarin-treated subjects with no baseline history of valvular heart disease $(n=58$, with a rate of $0.63 \%$ per year), an observation that lacks clinical plausibility.

A further evaluation was performed looking at the timing of MI relative to administration or discontinuation of the study drug. This analysis showed that $>30 \%$ of MI events in RE-LY occurred off study drug in all three treatment groups. ${ }^{12}$ However, there continued to be a numeric excess of first MI events in subjects randomized to dabigatran compared with warfarin more than 90 days after cessation of treatment, an observation that is not readily explainable (Table 6).

Adjudicated vascular death rates were $2.43 \%, 2.28 \%$, and $2.69 \%$ per year for the dabigatran $110 \mathrm{mg}$, dabigatran $150 \mathrm{mg}$, and warfarin treatment groups, respectively (Table 4). The risk of vascular death for dabigatran $150 \mathrm{mg}$ twice daily was significantly lower than for well-controlled warfarin (hazard ratio [HR] 0.85, 95\% CI 0.72-0.99, $P=0.04)$. In addition, the protocol-prespecified composite endpoint of stroke, systemic embolic events, MI, pulmonary embolism, and vascular death for dabigatran $150 \mathrm{mg}$ twice daily compared with warfarin had an HR of 0.84

Table 5 Effect of INR control on MI rates in warfarin-treated patients in RE-LY

\begin{tabular}{lll}
\hline & INR TTR $<\mathbf{6 5 \%}$ & INR TTR $\geq \mathbf{6 5 \%}$ \\
\hline Subject number $(\mathrm{n})$ & 2,595 & 3,194 \\
Subject years $(\mathrm{n})$ & $4,45 \mathrm{I}$ & 6,175 \\
Ml $(\mathrm{n}, \%$ per year) & $32(0.72)$ & $30(0.49)$ \\
\hline
\end{tabular}

Abbreviations: INR, international normalized ratio; MI, myocardial infarction; TTR, time in therapeutic range; RE-LY, Randomized Evaluation of Long-term anticoagulation therapY. 
Table 6 Timing of $\mathrm{MI}$ with respect to treatment in RE-LY, randomized set

\begin{tabular}{|c|c|c|c|}
\hline & $\begin{array}{l}\text { Dabigatran } \\
\text { II0 mg bid } \\
(\mathrm{n}=6,0 \mid 5) \\
\end{array}$ & $\begin{array}{l}\text { Dabigatran } \\
\text { I50 mg bid } \\
(n=6,076) \\
\end{array}$ & $\begin{array}{l}\text { Warfarin } \\
(n=6,022)\end{array}$ \\
\hline & n (\%) & n (\%) & n (\%) \\
\hline $\begin{array}{l}\text { Total number of MI } \\
\text { cases, } \mathrm{n}(\%)\end{array}$ & $87(1.5)$ & $89(1.5)$ & $66(1.1)$ \\
\hline $\begin{array}{l}\text { MI on or } \leq 6 \text { days off } \\
\text { study drug, } n(\%)\end{array}$ & $69(1.1)$ & $69(1.1)$ & $54(90.9)$ \\
\hline On study drug, n (\%) & $56(0.9)$ & $59(1.0)$ & $46(0.8)$ \\
\hline \multicolumn{4}{|l|}{ Off study drug, n (\%) } \\
\hline$\leq 6$ days off study drug & $13(0.2)$ & $10(0.2)$ & $8(0.1)$ \\
\hline$>6$ days off study drug & $17(0.3)$ & $20(0.3)$ & $12(0.2)$ \\
\hline 6 and $\leq 30$ days & $2(0.0)$ & $3(0.0)$ & $4(0.1)$ \\
\hline 30 and $\leq 90$ days & $2(0.0)$ & $3(0.0)$ & $2(0.0)$ \\
\hline$>90$ days & $13(0.2)$ & $14(0.2)$ & $6(0.1)$ \\
\hline $\begin{array}{l}\text { Randomized and not } \\
\text { treated, } \mathrm{n}(\%)\end{array}$ & $\mathrm{I}(0.0)$ & $0(0.0)$ & $0(0.0)$ \\
\hline
\end{tabular}

Abbreviations: bid, twice daily; MI, myocardial infarction; RE-LY, Randomized Evaluation of Long-term anticoagulation therapY.

(95\% CI 0.74-0.96, $P=0.009$ ). There were no significant differences between the groups with regard to rates of cardiovascular death, or the composite endpoints of MI and cardiovascular death or MI and all-cause mortality. The protocol-prespecified composite endpoint of "net clinical benefit" (all strokes, systemic embolic events, MI, pulmonary embolism, major bleeding, and all-cause death) favored both dabigatran doses, with rates of $7.34 \%$ per year with dabigatran $110 \mathrm{mg}$ twice daily, $7.11 \%$ per year with dabigatran $150 \mathrm{mg}$ twice daily, and $7.91 \%$ per year with warfarin (HR 0.92, 95\% CI 0.84-1.01, $P=0.09$ for dabigatran $110 \mathrm{mg}$ and HR $0.9,95 \%$ CI $0.82-0.99, P=0.02$ for dabigatran $150 \mathrm{mg}$ twice daily). ${ }^{12}$

\section{Subjects undergoing acute treatment}

or secondary prevention of VTE: individual trial data versus well-controlled warfarin

Two acute VTE treatment studies ( $\mathrm{n}=5,060)^{30,31}$ of 6 months' duration compared dabigatran versus warfarin for the treatment of acute VTE, and within each study there was a low incidence of definite ACS events during the treatment period, but there were more events in those treated with dabigatran $(0.3 \%)$ than in those treated with warfarin $(0.1 \%)$. In a secondary prevention trial of up to 3 years' duration comparing dabigatran versus warfarin for the prevention of recurrent VTEs ${ }^{28}$ nine MI events were reported in the $150 \mathrm{mg}$ twice daily dabigatran group versus one event in the warfarin group (Table 7). There was a higher prevalence

Table $7 \mathrm{CV}$ events in dabigatran VTE treatment, secondary VTE prophylaxis, and primary VTE prophylaxis in orthopedic surgery trials

\begin{tabular}{|c|c|c|c|c|c|c|c|c|c|c|}
\hline & \multicolumn{4}{|c|}{ Acute VTE treatment } & \multicolumn{4}{|c|}{ Secondary VTE prevention } & \multirow{2}{*}{\multicolumn{2}{|c|}{$\begin{array}{l}\text { Primary VTE } \\
\text { prevention after } \\
\text { orthopedic } \\
\text { surgery }^{13} \\
\text { RE-MOBILIZE, }{ }^{23} \\
\text { RE-MODEL, }^{21} \text { and } \\
\text { RE-NOVATE }^{22}\end{array}$}} \\
\hline & \multicolumn{2}{|c|}{ RE-COVER ${ }^{30}$} & \multicolumn{2}{|c|}{ RE-COVER $\|^{3 I}$} & \multicolumn{2}{|c|}{ RE-MEDYb,28 } & \multicolumn{2}{|c|}{ RE-SONATE ${ }^{\mathrm{b}, 29}$} & & \\
\hline & Dab & Warf & Dab & Warf & Dab & Warf & Dab & Plac & Dab & Enox \\
\hline Subjects, ${ }^{a} n$ & $1,226^{\mathrm{b}}$ & 1,266 & 1,280 & 1,288 & 1,430 & $\mathrm{I}, 426$ & 684 & 659 & 5,419 & 2,716 \\
\hline $\begin{array}{l}\text { Subjects with } \\
\text { definite/likely } \\
\text { ACS events, n (\%) }\end{array}$ & $4(0.3)$ & $3(0.2)$ & $5(0.4)$ & $3(0.2)$ & $13(0.9)$ & $3(0.2)$ & NR & NR & $42(0.8)$ & $20(0.7)$ \\
\hline $\begin{array}{l}\text { Subjects with definite } \\
\text { ACS events, } n(\%)\end{array}$ & $4(0.3)$ & $3(0.2)$ & $5(0.4)$ & I $(0.1)$ & $12(0.9)$ & $2(0.1)$ & $\mathrm{I}(0.1)$ & I $(0.2)$ & $28(0.5)$ & $17(0.6)$ \\
\hline $\mathrm{CV}$ death, $\mathrm{n}$ & 0 & 0 & 0 & 0 & 0 & 0 & 0 & 0 & NR & NR \\
\hline Ml events, $n$ & 3 & 2 & 5 & I & 9 & 1 & I & I & NR & NR \\
\hline Ischemia, angina, $\mathrm{n}$ & I & I & 0 & 0 & 3 & 1 & 0 & 0 & & \\
\hline Deaths, ${ }^{c}$ n (\%) & $\begin{array}{l}25 / 1,274 \\
(2.0)\end{array}$ & $\begin{array}{l}25 / I, 265 \\
(2.0)\end{array}$ & $\begin{array}{l}29 / 1,279 \\
(2.3)\end{array}$ & $\begin{array}{l}26 / 1,289 \\
(2.0)\end{array}$ & $17(1.2)$ & $19(1.3)$ & 0 & I $(0.2)$ & $16(0.3)$ & $6(0.2)$ \\
\hline
\end{tabular}

Notes: ${ }^{a}$ Number of subjects treated; bbased on number of patients randomized and treated with dabigatran; 'number of subjects randomized.

Abbreviations: ACS, acute coronary syndrome; CV, cardiovascular; Dab, dabigatran; Enox, enoxaparin; MI, myocardial infarction; NR, not reported; Plac, placebo; VTE, venous thromboembolism; Warf, warfarin; RE-COVER, A Randomized Trial of Dabigatran Versus Warfarin in the Treatment of Acute Venous Thromboembolism; RE-MODEL, Regulation of Coagulation in Orthopedic surgery to pRevent Deep venous thrombosis and pulmonary embolism; RE-NOVATE, Oral dabigatran versus enoxaparin for thromboprophylaxis after primary total hip arthroplasty; RE-MOBILIZE, prevention of venous thromboembolism after total knee arthroplasty trial; RE-MEDY, A Phase III, Randomised, Multicenter, Double-blind, Parallel-group, Active Controlled Study to Evaluate the Efficacy and Safety of Oral Dabigatran Etexilate (I50 mg Bid) Compared to Warfarin (INR 2.0-3.0) for the Secondary Prevention of Venous Thromboembolism; RE-SONATE, Twice-daily Oral Direct Thrombin Inhibitor Dabigatran Etexilate in the Long Term Prevention of Recurrent Symptomatic VTE. 
of baseline coronary risk factors, including hypertension, diabetes, and established coronary artery disease, in those treated with dabigatran than in those treated with warfarin in these studies.

\section{Comparisons with enoxaparin or placebo (in subjects undergoing primary and secondary prevention of VTE and subjects with ACS)}

Pooled analyses of individual subject data versus enoxaparin and placebo

In four studies comparing dabigatran $220 \mathrm{mg}$ once daily versus enoxaparin $^{21-23,25}$ (Figure 2) and two studies comparing dabigatran $150 \mathrm{mg}$ twice daily versus placebo ${ }^{29,32}$ (Figure 3A), point estimates for $\mathrm{MI}$ and composite endpoints that included MI were $<1.0$ and $>1.0$, respectively, although the CIs were wide. Similarly, conclusions regarding point estimates for cardiovascular and vascular death are limited by wide CIs due to the low number of events. Only one trial ${ }^{32}$ compared dabigatran $110 \mathrm{mg}$ twice daily versus placebo (Figure $3 \mathrm{~B}$ ).

\section{Subjects undergoing primary prevention of VTE:} individual trial data versus enoxaparin

In three VTE primary prevention studies, ie, RE-MODEL (Thromboembolism Prevention After Knee Surgery), RENOVATE (Oral dabigatran versus enoxaparin for thromboprophylaxis after primary total hip arthroplasty), and
RE-MOBILIZE (prevention of venous thromboembolism after total knee arthroplasty trial) in subjects undergoing elective total hip or knee joint replacement surgery $(n=8,135)$, rates of adjudicated definite/likely ACS events were low and similar with dabigatran (150 mg or $220 \mathrm{mg}$ once daily groups combined) or enoxaparin $(0.8 \%$ versus $0.7 \%$, respectively, Table 7$) .{ }^{13}$ Investigator-reported ACS event data are available for all four primary VTE prevention studies, including the RE-NOVATE II study which investigated the $220 \mathrm{mg}$ dose of dabigatran without central adjudication of ACS events. In the pooling of the four trials, ACS events identified by investigators locally occurred in $0.16 \%$ of patients in the dabigatran $220 \mathrm{mg}$ once daily group compared with $0.35 \%$ in the enoxaparin group. ${ }^{13}$

\section{Subjects undergoing secondary prevention of VTE: individual trial data versus placebo}

In a secondary VTE prevention study comparing dabigatran versus placebo, ${ }^{29}$ only one MI was reported in each treatment group. All-cause mortality rates were similar with dabigatran and the comparator treatment, predominantly warfarin (Table 7).

\section{Subjects with ACS: individual trial data versus placebo}

In the Phase II RE-DEEM (Randomized Dabigatran Etexilate Dose Finding Study In Patients With Acute Coronary Syndromes) dose-ranging ACS study, ${ }^{32}$ almost all subjects

\section{Source}

MI (including silent)

Stroke

Vascular death

CV death

MI (including silent), CV death

Nonfatal stroke

MI (including silent), nonfatal stroke, CV death

MI (including silent), stroke, vascular death

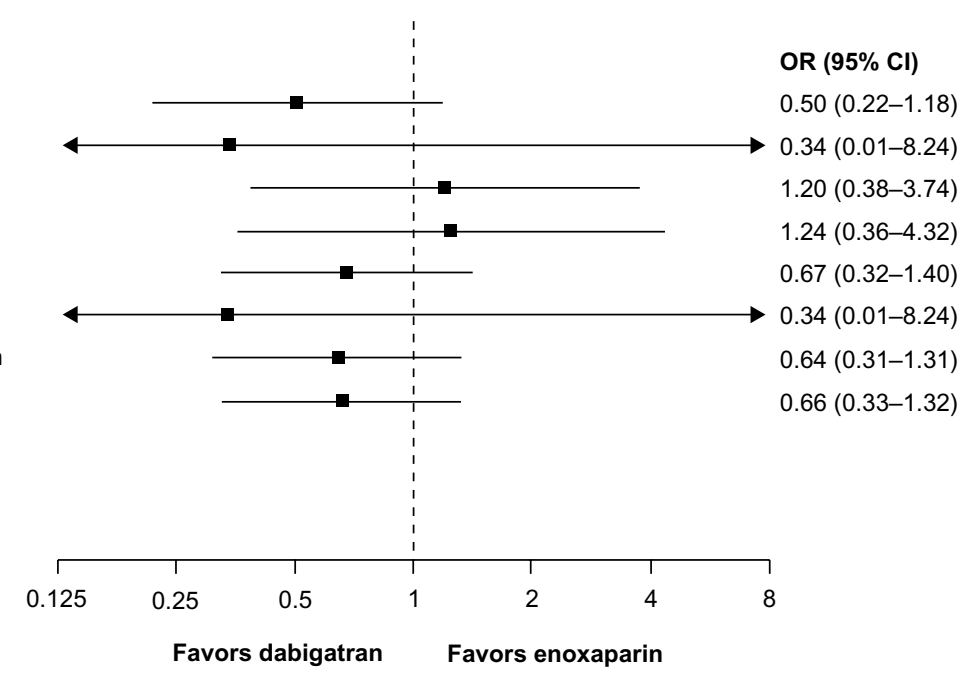

Favors dabigatran Favors enoxaparin

Figure $2 \mathrm{CV}$ events for dabigatran $220 \mathrm{mg}$ once daily $(n=3,692)$ versus enoxaparin $(n=3,719)$ in treated patients (randomization to study termination). This analysis includes RE-MOBILIZE, RE-MODEL, RE-NOVATE, and RE-NOVATE II. ${ }^{21-23,25}$

Abbreviations: $\mathrm{Cl}$, confidence interval; CV, cardiovascular; MI, myocardial infarction; OR, odds ratio; RE-MODEL, Regulation of Coagulation in Orthopedic surgery to pRevent Deep venous thrombosis and pulmonary embolism; RE-NOVATE, Oral dabigatran versus enoxaparin for thromboprophylaxis after primary total hip arthroplasty; RE-MOBILIZE, prevention of venous thromboembolism after total knee arthroplasty trial; RE-MEDY, A Phase III, Randomised, Multicenter, Double-blind, Parallel-group, Active Controlled Study to Evaluate the Efficacy and Safety of Oral Dabigatran Etexilate (I50 mg Bid) Compared to Warfarin (INR 2.0-3.0) for the Secondary Prevention of Venous Thromboembolism. 
A

\section{Source}

MI (including silent)

Stroke

Vascular death

CV death

MI (including silent), CV death

Nonfatal stroke

MI (including silent), nonfatal stroke, CV death

MI (including silent), stroke, vascular death

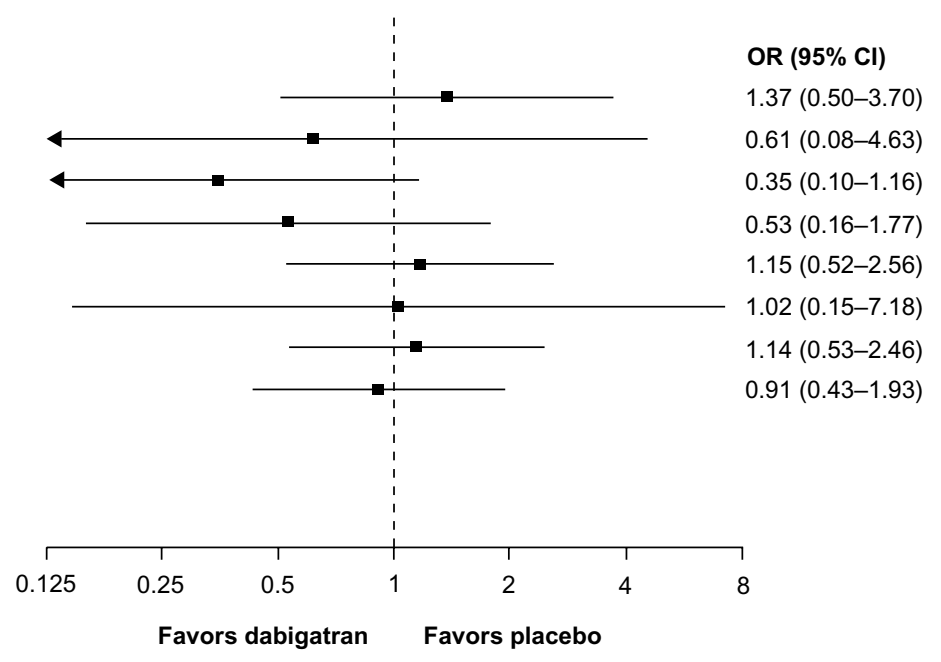

B

Source

MI (including silent)

Stroke

Vascular death

CV death

MI (including silent), CV death

Nonfatal stroke*

MI (including silent), nonfatal stroke, CV death

MI (including silent), stroke, vascular death

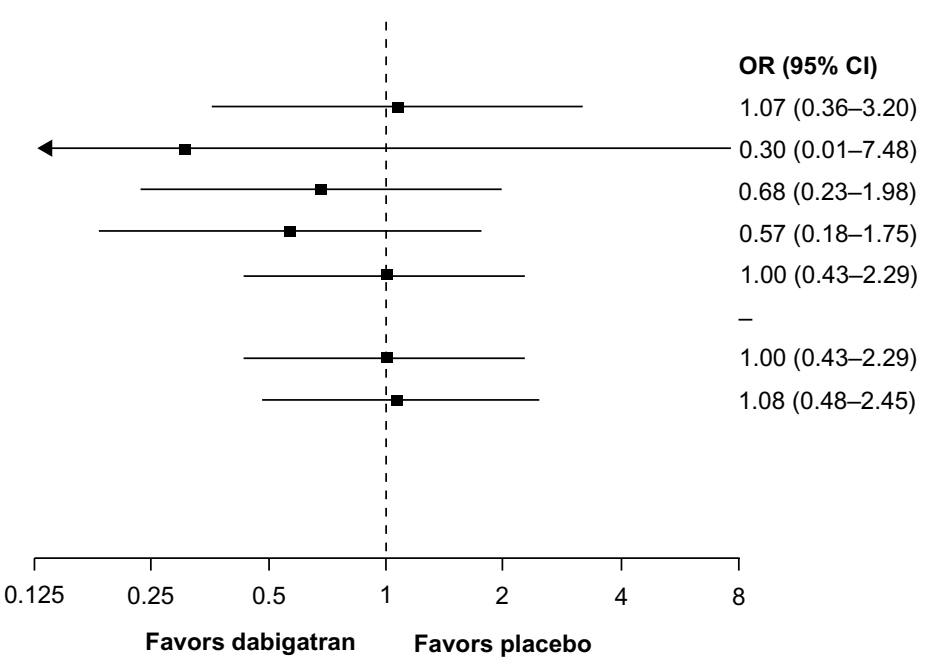

Figure 3 (A) CV events for dabigatran $150 \mathrm{mg}$ twice daily $(\mathrm{n}=1,023)$ versus placebo $(\mathrm{n}=1,03 \mathrm{I})$ in treated patients (randomization to study termination), (B) CV events for dabigatran II $0 \mathrm{mg}$ twice daily $(n=406)$ versus placebo $(n=37 \mathrm{I})$ in treated patients (randomization to study termination). (A) This analysis includes RE-SONATE ${ }^{29}$ and RE-DEEM. ${ }^{32}$ (B) This analysis includes RE-DEEM. ${ }^{32}$

Note: *In RE-DEEM no nonfatal strokes were observed in the dabigatran $110 \mathrm{mg}$ twice daily treatment group and there was one in the placebo group; therefore OR cannot be calculated.

Abbreviations: $\mathrm{Cl}$, confidence interval; CV, cardiovascular; MI, myocardial infarction; OR, odds ratio; VTE, venous thromboembolism; RE-SONATE, Twice-daily Oral Direct Thrombin Inhibitor Dabigatran Etexilate in the Long Term Prevention of Recurrent Symptomatic VTE; RE-DEEM, RandomizEd Dabigatran Etexilate Dose Finding Study in Patients With Acute Coronary Syndromes Post Index Event With Additional Risk Factors for Cardiovascular Complications Also Receiving Aspirin and Clopidogrel: Multicentre, Prospective, Placebo Controlled, Cohort Dose Escalation Study.

received dual antiplatelet therapy ( $>95 \%$ at 1 month) in addition to dabigatran (over the dose range 50-150 mg twice daily) or placebo (Supplementary Table 3). MIs occurred at a rate of $1.6 \%$ for placebo and $3.0 \%, 2.7 \%, 1.7 \%$, and $2.3 \%$ for dabigatran doses of 50, 75, 110, and $150 \mathrm{mg}$ twice daily, respectively. Two fatal MIs $(0.5 \%)$ occurred in each of the placebo and dabigatran $50 \mathrm{mg}$ twice daily and $75 \mathrm{mg}$ twice daily groups. There were no fatal MIs in the dabigatran $110 \mathrm{mg}$ twice daily and $150 \mathrm{mg}$ twice daily groups. There were three strokes in the placebo group, one in the dabigatran $75 \mathrm{mg}$ twice daily group, and none in the other dabigatran dosing groups. Cardiovascular and all-cause mortality rates were lowest in the $110 \mathrm{mg}$ twice daily and $150 \mathrm{mg}$ twice daily groups compared with the lower dose dabigatran and placebo groups (Supplementary Table 3).

\section{Discussion}

Findings from our review and analyses of all comparative Phase II and III clinical trials of dabigatran etexilate clearly indicate that the rate of MI with well-controlled warfarin (for stroke prevention in patients with atrial fibrillation and acute VTE treatment or secondary VTE prevention) is lower than with dabigatran $150 \mathrm{mg}$ twice daily. This is consistent with the results from RE-LY, which contributed to the majority 
of the data in these analyses. When comparing MI rates for dabigatran-treated patients with those for patients treated with enoxaparin or placebo, no significant difference could be observed, supporting the conclusion that dabigatran is not causing MI but rather that dabigatran is less effective than well-controlled warfarin at preventing MI; ${ }^{15,35}$ also supporting the conclusion that warfarin is protective in preventing $\mathrm{MI}$ is the observation that warfarin-treated patients in RE-LY with better INR control (TTR $\geq 65 \%$ ) had lower rates of MI than those with worse INR control (TTR <65\%). Additionally, in all patient populations treated with dabigatran, the $\mathrm{MI}$ rates were low and any increase in the rates of MI compared with warfarin were counterbalanced by an improved overall clinical benefit due to a reduction in stroke, and/or lower rates of other cardiovascular outcome events and/or overall cardiovascular mortality in those receiving dabigatran.

The rationale for conducting this detailed review of individual and pooled study results was based on the observation of a nonsignificant increase in the number of MI events with dabigatran versus warfarin in RE-LY ${ }^{1}$ and a recently published meta-analysis that included only selected dabigatran clinical trial data. ${ }^{16}$ This MI imbalance, although small (1.5 excess events per 1,000 subjects per year), could not be explained by differences in baseline characteristics, including previous coronary artery disease or MI, diabetes, hypertension, or other baseline therapies. The meta-analysis by Uchino and Hernandez ${ }^{16}$ included trials with different patient types and comparators, did not utilize individual patient data, and did not include analyses according to differences in baseline characteristics and risk factors, which therefore resulted in significant limitations and raised questions about its reliability and validity. The overall MI rates in RE-LY in each treatment group were low $(0.6 \%-0.8 \%$ per year) and similar to those observed in other recent trials ${ }^{3-11}$ in subjects with atrial fibrillation $(0.55 \%-1.4 \%)$ receiving warfarin, antiplatelet agents, or other new oral anticoagulants; however, we still believed a thorough and as comprehensive as possible evaluation of MI rates and cardiovascular endpoint data was necessary. Due to unlimited access to the trial databases of Boehringer Ingelheim, we were able to complete this comprehensive and complete evaluation ${ }^{1,2,20-32}$ addressing the limitations of other recent meta-analyses and publications.

The results in different subject populations and with different comparators (warfarin, enoxaparin, and placebo), when reviewed as individual studies or as pooled analyses of individual patient data, were consistent. In individual studies of the treatment of stroke associated with atrial fibrillation and indications other than atrial fibrillation, all stroke (ischemic and hemorrhagic), all-cause, and cardiovascular mortality rates were similar or lower with dabigatran than with warfarin. There was a consistent imbalance in MI rates between dabigatran and warfarin for all evaluated populations, although the absolute risk differences were small. The finding in RE-LY that warfarin-treated patients with better INR control (TTR $\geq 65 \%$ ) had approximately 30\% lower annual MI rates than warfarin-treated subjects with poorer INR control (TTR $<65 \%$ ) supports the concept that better warfarin INR control is associated with better MI prevention. The different mechanisms of action of warfarin and dabigatran may have a role in the different profiles observed for these drugs. The lack of any negative effect on myocardial ischemic events in the studies comparing dabigatran versus enoxaparin or placebo in over 10,000 patients strongly supports the position that MI is not an adverse effect of dabigatran, but rather that wellcontrolled warfarin seems to have a greater beneficial effect in preventing MI than dabigatran. Of interest, enoxaparin remains a guideline-recommended therapy for the treatment of acute MI and we observed no differences in the occurrence of $\mathrm{MI}$ in patients exposed to dabigatran or enoxaparin. A network meta-analysis of dabigatran versus placebo and aspirin treatment indicated no difference in the risk of MI, which is also supportive of this hypothesis. ${ }^{36}$ Furthermore, in an evaluation of a factor Xa inhibitor (rivaroxaban) compared with a well-controlled warfarin comparison (TTR was 64\% in the North American population), this trend toward a lower potency of the new oral anticoagulant regarding MI prevention was also seen (HR 1.15, 95\% CI 0.74-1.80). ${ }^{37}$ Additionally, a similar trend was recently reported for edoxaban in the HOKUSAI-VTE study. ${ }^{38}$ Therefore, it is reasonable that our results reflect the beneficial effects of well-controlled warfarin (median TTR 67.3\%) for the prevention of myocardial ischemia. ${ }^{35}$ Several studies have shown that warfarin has a protective effect against MI compared with nonwarfarin anticoagulants in patients with atrial fibrillation who are prescribed anticoagulation for stroke prevention. ${ }^{3,15,39}$ Other studies have shown that warfarin plus aspirin is useful for the management of patients with coronary artery disease, particularly in the secondary prevention setting. ${ }^{35,40,41}$

When looking at specific subgroups in the RE-LY trial, interestingly, the imbalance in MI events in the pooled analysis of studies versus warfarin was predominantly driven by the results of RE-LY. The very low MI rate in warfarin-treated RE-LY subjects with baseline valvular heart disease $(0.3 \%)$ may have skewed the results. Indeed, the rate was half that observed in warfarin-treated subjects without a history of 
valvular heart disease $(0.6 \%)$. A lower MI rate in subjects with valvular heart disease who are at high risk for morbidity and mortality does not seem medically plausible ${ }^{42}$ since the actual MI rate $(0.3 \%)$ in this subgroup of warfarin subjects was lower than any reported MI rate in all major recent studies of subjects with atrial fibrillation $(0.55 \%-1.4 \%),{ }^{3-11}$ the presence of valvular heart disease is indicative of a greater degree of cardiovascular comorbidity rather than its absence. Additionally, the RE-LY study exclusion criteria did not prespecify quantitative measures to identify nonhemodynamically significant valvular heart disease, making it a subjective, investigator-dependent characterization. Importantly, it should also be noted that there was no difference in MI rates comparing dabigatran versus warfarin in over 14,000 (78\%) of the RE-LY subjects without a baseline history of valvular heart disease.

Investigation of the timing of myocardial ischemic events in relation to treatment, important in the assessment of causality, showed that a portion of the observed excess MI rates with dabigatran in RE-LY was evident more than 3 months after discontinuation of the study drug. This suggests that this difference may be due to underlying imbalances between the treatment groups rather than the treatments themselves. In support of this, it is notable that $>30 \%$ of the MI events in the dabigatran groups occurred off treatment, by which time most subjects were receiving oral anticoagulation with a nonstudy drug. ${ }^{12}$ Despite a shorter half-life of dabigatran compared with warfarin, there was no difference in the number of MI events within the first 30 days of stopping either treatment, indicating lack of any rebound effect. A recently published study investigating whether a rebound effect could be present in patients on dabigatran in RE-MOBILIZE, REMODEL, RE-NOVATE, and RE-NOVATE II detected no increased ACS signal with dabigatran etexilate compared with enoxaparin during or after treatment. ${ }^{13}$

There is no evidence in animal models that dabigatran causes vascular injury. Instead, studies show that dabigatran has antithrombotic and antiatherosclerotic properties and suggest that dabigatran treatment may limit atherosclerosis progression and preserve vessel lumen patency. ${ }^{43-46}$

The findings of the RE-LY trial need to be considered from both clinical and public health perspectives. While RE-LY indicated a modest, nonsignificant increase in MI compared with warfarin, this was more than counterbalanced by significant beneficial effects on stroke reduction (six fewer events per 1,000 subjects per year) and lower observed rates of cardiovascular mortality (five fewer events per 1,000 subjects per year) and total mortality, compared with warfarin. ${ }^{44}$ The RE-LY protocol prespecified a composite outcome endpoint of net clinical benefit (all strokes, systemic embolic events, MI, pulmonary embolism, major bleeding, and all-cause death), the occurrence of which favored both dabigatran doses. ${ }^{12}$ In RE-LY subjects with a prior history of coronary artery disease or previous MI, the relative risk of MI with dabigatran versus warfarin and the net clinical benefit of dabigatran over warfarin were similar compared with the group without a prior history of coronary artery disease at baseline. ${ }^{12}$ This means that the treatment effects of dabigatran on composite major clinical outcomes (eg, stroke/systemic embolic events, major bleeding, and MI) were consistent in patients at higher (ie, patients with previous MI or coronary artery disease) and lower risk of myocardial ischemic events. ${ }^{12}$ Additionally, warfarin-treated subjects in RE-LY with better INR control had lower MI rates than warfarin-treated subjects with poorer INR control.

In the recently published RELY-ABLE (Long Term Multi-center Extension of Dabigatran Treatment in Patients With Atrial Fibrillation Who Completed RE-LY Trial) safety follow-up of RE-LY, 2.3 years of additional treatment with dabigatran was evaluated (total mean follow-up time of 4.3 years). The annual rates of MI were low and similar between the groups, at $0.69 \%$ and $0.72 \%$ per year for $150 \mathrm{mg}$ twice daily and $110 \mathrm{mg}$ twice daily, respectively. These low event rates for MI, as well as for all other evaluated outcomes, were consistent with the rates seen in RE-LY even after a long duration of exposure to dabigatran treatment. ${ }^{47}$

As a class, direct thrombin inhibitors have previously been shown to be effective in the treatment of myocardial ischemia. ${ }^{48}$ The parenteral direct thrombin inhibitor, bivalirudin, was shown to be superior to heparin for the prevention of death or MI in subjects with ACS. ${ }^{49}$ Bivalirudin was also shown to be more effective than heparin in subjects with ST-segment elevation MI undergoing percutaneous coronary intervention. ${ }^{50}$ The first oral direct thrombin inhibitor, ximelagatran, was shown to be effective in reducing the occurrence of new ischemic events when given with aspirin in subjects who had sustained a recent MI. ${ }^{18}$ The rates for MI were similar comparing ximelagatran and warfarin for the prevention of stroke in subjects with atrial fibrillation. ${ }^{51}$

We note the limitations inherent in interpretation of this post hoc analysis of the efficacy and safety of dabigatran. First, the included studies were conducted in different study populations with different baseline characteristics (eg, age, concomitant diseases, and treatment) and, for warfarin, varying levels of control measured as TTR. Second, treatment duration and follow-up periods with dabigatran varied 
between the trials. Third, different processes were used to identify outcome events and adjudication. Finally, trials with a longer duration (eg, RE-LY) have had a higher impact on the results of this analysis. In contrast with a previous meta-analysis, ${ }^{16}$ we tried to minimize the impact of these variables by only pooling data using the same comparator (ie, warfarin, enoxaparin, or placebo). Thus, the results of the pooled analysis can be considered hypothesis-generating but not confirmatory.

Our findings greatly expand the analysis recently reported by Uchino and Hernandez, ${ }^{16}$ in which summary trial data from only seven dabigatran trials ( $\mathrm{n}=31,097$ subjects) were pooled, and their analyses were conducted pooling all comparators, subject populations, indications, and dabigatran dosage, including some doses that are apparently not clinically effective. In comparison, the current analysis relies on individual subject data and a more robust statistical approach, based on pooling of trials with similar comparators and doses, as well as use of a multifactorial analysis adjusting for differing risk factors concerning various outcome measures.

\section{Conclusion}

Based on the findings from our analyses and available clinical and preclinical investigations, we conclude that, although MI occurs more frequently in dabigatran-treated subjects than in warfarin-treated subjects, MI is not an adverse drug reaction resulting from administration of dabigatran. Further, dabigatran had an overall positive benefit-risk ratio when the composite endpoints of efficacy and safety are assessed in each of the clinical indications evaluated, including all comparisons with well-controlled warfarin.

\section{Disclosure}

This analysis was sponsored by Boehringer Ingelheim. Boehringer Ingelheim and its affiliates were responsible for the design, conduct, and funding of all of the studies, as well as collection and management of the data. Editorial assistance was provided by Elena Garonna from PAREXEL, with funding from Boehringer Ingelheim. Andreas Clemens, Mandy Fraessdorf, and Jeffrey Friedman are employees of Boehringer Ingelheim.

\section{References}

1. Connolly SJ, Ezekowitz MD, Yusuf S, Reilly PA, Wallentin L. Newly identified events in the RE-LY trial. N Engl J Med. 2010;363(19): 1875-1876.

2. Connolly SJ, Ezekowitz MD, Yusuf S, et al. Dabigatran versus warfarin in patients with atrial fibrillation. $N$ Engl J Med. 2009;361(12): 1139-1151.
3. Olsson SB. Stroke prevention with the oral direct thrombin inhibitor ximelagatran compared with warfarin in patients with non-valvular atrial fibrillation (SPORTIF III): randomised controlled trial. Lancet. 2003;362(9397):1691-1698.

4. Albers GW, Diener HC, Frison L, et al. Ximelagatran vs warfarin for stroke prevention in patients with nonvalvular atrial fibrillation: a randomized trial. JAMA. 2005;293(6):690-698.

5. Connolly S, Pogue J, Hart R, et al. Clopidogrel plus aspirin versus oral anticoagulation for atrial fibrillation in the Atrial Fibrillation Clopidogrel Trial with Irbesartan for prevention of Vascular Events (ACTIVE W): a randomised controlled trial. Lancet. 2006;367(9526):1903-1912.

6. Mant J, Hobbs FD, Fletcher K, et al. Warfarin versus aspirin for stroke prevention in an elderly community population with atrial fibrillation (the Birmingham Atrial Fibrillation Treatment of the Aged Study, BAFTA): a randomised controlled trial. Lancet. 2007;370(9586): 493-503.

7. Bousser MG, Bouthier J, Buller HR, et al. Comparison of idraparinux with vitamin $\mathrm{K}$ antagonists for prevention of thromboembolism in patients with atrial fibrillation: a randomised, open-label, non-inferiority trial. Lancet. 2008;371(9609):315-321.

8. Connolly SJ, Pogue J, Hart RG, et al. Effect of clopidogrel added to aspirin in patients with atrial fibrillation. N Engl J Med. 2009;360(20): 2066-2078.

9. Connolly SJ, Eikelboom J, Joyner C, et al. Apixaban in patients with atrial fibrillation. N Engl J Med. 2011;364(9):806-817.

10. Patel MR, Mahaffey KW, Garg J, et al. Rivaroxaban versus warfarin in nonvalvular atrial fibrillation. $N$ Engl $J$ Med. 2011;365(10): $883-891$.

11. Granger CB, Alexander JH, McMurray JJ, et al. Apixaban versus warfarin in patients with atrial fibrillation. $N$ Engl $J$ Med. 2011;365(11):981-992.

12. Hohnloser SH, Oldgren J, Yang S, et al. Myocardial ischemic events in patients with atrial fibrillation treated with dabigatran or warfarin in the RE-LY (Randomized Evaluation of Long-Term Anticoagulation Therapy) trial. Circulation. 2012;125(5):669-676.

13. Eriksson BI, Smith JJ, Caprini J, et al. Evaluation of the acute coronary syndrome safety profile of dabigatran etexilate in patients undergoing major orthopedic surgery: findings from four Phase 3 trials. Thromb Res. 2012;130(3):396-402.

14. Correia LC, Lopes AA. Dabigatran and myocardial infarction: meta-illusion? Arch Intern Med. 2012;172(10):823.

15. Lip GY, Lane DA. Does warfarin for stroke thromboprophylaxis protect against $\mathrm{MI}$ in atrial fibrillation patients? $\mathrm{Am} \mathrm{J} \mathrm{Med}$. 2010;123(9): 785-789.

16. Uchino K, Hernandez AV. Dabigatran association with higher risk of acute coronary events: meta-analysis of noninferiority randomized controlled trials. Arch Intern Med. 2012;172(5):397-402.

17. Jacobs JM, Stessman J. Dabigatran: do we have sufficient data?: comment on "Dabigatran association with higher risk of acute coronary events". Arch Intern Med. 2012;172(5):403-404.

18. Wallentin L, Wilcox RG, Weaver WD, et al. Oral ximelagatran for secondary prophylaxis after myocardial infarction: the ESTEEM randomised controlled trial. Lancet. 2003;362(9386):789-797.

19. Lip GY, Rasmussen LH, Olsson SB, et al. Oral direct thrombin inhibitor AZD0837 for the prevention of stroke and systemic embolism in patients with non-valvular atrial fibrillation: a randomized dose-guiding, safety, and tolerability study of four doses of AZD0837 vs vitamin K antagonists. Eur Heart J. 2009;30(23):2897-2907.

20. Eriksson BI, Dahl OE, Buller HR, et al. A new oral direct thrombin inhibitor, dabigatran etexilate, compared with enoxaparin for prevention of thromboembolic events following total hip or knee replacement: the BISTRO II randomized trial. J Thromb Haemost. 2005;3(1):103-111.

21. Eriksson BI, Dahl OE, Rosencher N, et al. Oral dabigatran etexilate vs subcutaneous enoxaparin for the prevention of venous thromboembolism after total knee replacement: the RE-MODEL randomized trial. $J$ Thromb Haemost. 2007;5(11):2178-2185. 
22. Eriksson BI, Dahl OE, Rosencher N, et al. Dabigatran etexilate versus enoxaparin for prevention of venous thromboembolism after total hip replacement: a randomised, double-blind, non-inferiority trial. Lancet. 2007;370(9591):949-956.

23. Ginsberg JS, Davidson BL, Comp PC, et al. Oral thrombin inhibitor dabigatran etexilate vs North American enoxaparin regimen for prevention of venous thromboembolism after knee arthroplasty surgery. $J$ Arthroplasty. 2009;24(1):1-9.

24. Fuji T, Fuijita S, Ujihira T, Sato T. Dabigatran etexilate prevents venous thromboembolism after total knee arthroplasty in Japanese patients with a safety profile comparable to placebo. J Arthroplasty. 2010;25(8): 1267-1274.

25. Eriksson BI, Dahl OE, Huo $\mathrm{MH}$, et al. Oral dabigatran versus enoxaparin for thromboprophylaxis after primary total hip arthroplasty (RE-NOVATE II*). A randomised, double-blind, non-inferiority trial. Thromb Haemost. 2011;105(4):721-729.

26. Ezekowitz MD, Reilly PA, Nehmiz G, et al. Dabigatran with or without concomitant aspirin compared with warfarin alone in patients with nonvalvular atrial fibrillation (PETRO Study). Am J Cardiol. 2007;100(9): 1419-1426.

27. Tomimori H, Yamamura N, Adachi T. Open label, randomized exploratory, dose response study of the pharmacodynamics and safety of BIBR 1148 (110 mg bid and $150 \mathrm{mg}$ bid) for 12 weeks in patients with non-valvualr atrial fibrillation in comparison to warfarin. 2007. Study Number 1160.49. Report number U07-3126. Boehringer Ingelheim Internal Report.

28. Schulman S, Eriksson H, Goldhaber SZ. Dabigatran or warfarin for extended maintenance therapy of venous thromboembolism (abstract O-TH-033). J Thromb Haemost. 2011;9 Supp1 2:731-732.

29. Schulman S, Baanstra D, Eriksson H. Dabigatran versus placebo for extended maintenance therapy of venous thromboembolism (abstract O-MO-037). J Thromb Haemost. 2011;9 Suppl 2:22.

30. Schulman S, Kearon C, Kakkar AK, et al. Dabigatran versus warfarin in the treatment of acute venous thromboembolism. $N$ Engl J Med. 2009;361(24):2342-2352.

31. Schulman S, Kakkar AK, Schellong S. A randomized trial of dabigatran versus warfarin in the treatment of acute venous thromboembolism (RE-COVER II). ASH Annual Meeting Abstracts. 2011;118:A205.

32. Oldgren J, Budaj A, Granger CB, et al. Dabigatran versus placebo in patients with acute coronary syndromes on dual antiplatelet therapy: a randomized, double-blind, phase II trial. Eur Heart J. 2011;32(22): 2781-2789.

33. Eriksson BI, Dahl OE, Ahnfelt L, et al. Dose escalating safety study of a new oral direct thrombin inhibitor, dabigatran etexilate, in patients undergoing total hip replacement: BISTRO I. J Thromb Haemost. 2004;2(9):1573-1580.

34. PETRO-EX Investigators. Safety and efficacy of extended exposure to several doses of a new oral direct thrombin inhibitor dabigatran etexilate in atrial fibrillation. Cerebrovasc Dis. 2006;21 Suppl 4:2.

35. Rothberg MB, Celestin C, Fiore LD, Lawler E, Cook JR. Warfarin plus aspirin after myocardial infarction or the acute coronary syndrome: meta-analysis with estimates of risk and benefit. Ann Intern Med. 2005;143(4):241-250.

36. Roskell NS, Lip GY, Noack H, Clemens A, Plumb JM. Treatments for stroke prevention in atrial fibrillation: a network meta-analysis and indirect comparisons versus dabigatran etexilate. Thromb Haemost. 2010;104(6):1106-1115.
37. Johnson and Johnson. Slides for the September 8, 2011 Meeting of the Cardiovascular and Renal Drugs Advisory Committee, slide No 129 and 153, 2011.

38. Büller HR, Décousus H, Grosso MA, et al. Edoxaban versus warfarin for the treatment of symptomatic venous thromboembolism. $N$ Engl J Med. September 1, 2013 [Epub ahead of print.].

39. Lopes RD, Starr A, Pieper CF, et al. Warfarin use and outcomes in patients with atrial fibrillation complicating acute coronary syndromes. Am J Med. 2010;123(2):134-140.

40. Hurlen M, Abdelnoor M, Smith P, Erikssen J, Arnesen H. Warfarin, aspirin, or both after myocardial infarction. NEngl J Med. 2002;347(13): 969-974.

41. Andreotti F, Testa L, Biondi-Zoccai GG, Crea F. Aspirin plus warfarin compared with aspirin alone after acute coronary syndromes: an updated and comprehensive meta-analysis of 25,307 patients. Eur Heart J. 2006;27(5):519-526.

42. Breithart G, Baumgartner H, Berkowitz SD, et al. Characteristics and outcomes of patients with atrial fibrillation and significant valvular lesions experience from the ROCKET AF trial. J Am Coll Cardiol. 2013;61(Suppl 10):E282.

43. Kadoglou NP, Moustardas P, Katsimpoulas M, et al. The beneficial effects of a direct thrombin inhibitor, dabigatran etexilate, on the development and stability of atherosclerotic lesions in apolipoprotein E-deficient mice: dabigatran etexilate and atherosclerosis. Cardiovasc Drugs Ther. 2012;26(5):367-374.

44. Lee IO, Kratz MT, Schirmer SH, Baumhakel M, Bohm M. The effects of direct thrombin inhibition with dabigatran on plaque formation and endothelial function in apolipoprotein E-deficient mice. J Pharmacol Exp Ther. 2012;343(2):253-257.

45. Preusch M, Wijelath ES, Murray J. Dabigatran etexilate, a new oral thrombin inhibitor, retards the initiation and progression of atherosclerotic lesions and inhibits the expression of oncostatin $\mathrm{M}$ in apolipoprotein E-deficient mice. Arterioscl Thromb Vasc Biol. 2010;30:E185.

46. van Ryn J, Dietz T, Kuritsch I. Effect of direct thrombin inhibitor, dabigatran, on arterial thrombosis when given in combination with aspirin (ASA) in a cyclic flow model of anaesthesised pigs (abstract PP_MO-347). J Thromb Haemost. 2009;7 Suppl 2:435.

47. Connolly SJ, Wallentin L, Ezekowitz MD, et al. The Long Term MultiCenter Observational Study of Dabigatran Treatment in Patients with Atrial Fibrillation: (RELY-ABLE) Study. Circulation. June 14, 2013. [Epub ahead of print.]

48. Direct thrombin inhibitors in acute coronary syndromes and during percutaneous coronary intervention: design of a meta-analysis based on individual patient data. Direct Thrombin Inhibitor Trialists' Collaborative Group. Am Heart J. 2001;141(1):E2.

49. Stone GW, Witzenbichler B, Guagliumi G, et al. Bivalirudin during primary PCI in acute myocardial infarction. N Engl J Med. 2008;358(21): 2218-2230

50. Stone GW, Witzenbichler B, Guagliumi G, et al. Heparin plus a glycoprotein IIb/IIIa inhibitor versus bivalirudin monotherapy and paclitaxel-eluting stents versus bare-metal stents in acute myocardial infarction (HORIZONS-AMI): final 3-year results from a multicentre, randomised controlled trial. Lancet. 2011;377(9784):2193-2204.

51. Diener HC. Stroke prevention using the oral direct thrombin inhibitor ximelagatran in patients with non-valvular atrial fibrillation. Pooled analysis from the SPORTIF III and V studies. Cerebrovasc Dis. 2006;21(4):279-293. 


\section{Supplementary tables}

Table SI Patient characteristics

\begin{tabular}{|c|c|c|c|c|c|c|}
\hline \multirow[t]{2}{*}{ Trial } & \multirow[t]{2}{*}{ Age, mean (SD) } & \multirow[t]{2}{*}{ Males, \% } & \multicolumn{4}{|c|}{ Concomitant disorders, \% (n/N) } \\
\hline & & & Prior CAD & Prior MI & Diabetes & Hypertension \\
\hline BISTRO $\|^{20}$ & $65.9(10.6)$ & 38.9 & $4.1(80 / 1,949)$ & $\mathrm{I} .4(28 / \mathrm{I}, 949)$ & $3.8(74 / 1,949)$ & $38.0(740 / 1,949)$ \\
\hline RE-MODEL ${ }^{21}$ & $67.7(8.9)$ & 34.0 & $11.9(247 / 2,075)$ & $1.4(29 / 2,076)$ & II.2(232/2,075) & $59.4(1,232 / 2,075)$ \\
\hline RE-NOVATE 22 & $63.9(10.8)$ & 43.6 & $8.9(309 / 3,459)$ & $0.8(27 / 3,463)$ & 7.I $(247 / 3,458)$ & $46.3(1,601 / 3,460)$ \\
\hline RE-MOBILIZE ${ }^{23}$ & $66.1(9.5)$ & 42.3 & I I.2 (292/2,596) & I.7 $(45 / 2,596)$ & $15.8(410 / 2,596)$ & $62.6(1,625 / 2,596)$ \\
\hline Japanese TKR ${ }^{24}$ & $71.6(7.8)$ & 17.0 & $7.2(37 / 5 \mid 2)$ & $0(0 / 5 \mid 2)$ & $15.8(8|/ 5| 2)$ & $59.6(305 / 512)$ \\
\hline RE-NOVATE $\|^{25}$ & $62.0(11.4)$ & 48.2 & $6.4(129 / 2,011)$ & $0.5(1 \mathrm{I} / 2,013)$ & $8.4(I 68 / 2,01 I)$ & 46.I $(927 / 2,012)$ \\
\hline PETRO $^{26}$ & $69.7(8.2)$ & 81.9 & $61.0(306 / 502)$ & NA & $25.1(126 / 502)$ & $70.9(356 / 502)$ \\
\hline Japanese $\mathrm{AF}^{27}$ & $68.4(8.6)$ & 88.0 & $24.1(40 / 166)$ & $6.0(10 / 166)$ & $27.7(46 / 166)$ & $69.9(116 / 166)$ \\
\hline RE-LY',2 & $71.5(8.7)$ & 63.6 & $27.8(5,010 / 18,040)$ & $16.6(2,994 / 18,040)$ & $23.3(4,204 / 18,040)$ & $78.8(\mid 4,221 / 18,040)$ \\
\hline RE-MEDY 28 & $54.6(15.2)$ & 61.0 & $7.2(207 / 2,856)$ & I.2 (34/2,856) & $9.0(258 / 2,856)$ & $38.6(1,102 / 2,856)$ \\
\hline RE-SONATE ${ }^{29}$ & $55.8(15.3)$ & 55.5 & $6.8(91 / 1,343)$ & $2.0(27 / I, 343)$ & $8.0(107 / 1,343)$ & $38.8(52 \mathrm{I} / \mathrm{I}, 343)$ \\
\hline RE-COVER ${ }^{30}$ & $54.7(16.0)$ & 58.4 & $6.5(166 / 2,539)$ & $1.4(35 / 2,539)$ & $8.3(211 / 2,539)$ & $35.9(911 / 2,539)$ \\
\hline RE-COVER III & $54.9(16.2)$ & 60.6 & $7.7(198 / 2,568)$ & I.3 $(33 / 2,568)$ & $9.8(25 \mathrm{I} / 2,568)$ & $35.6(9 / 3 / 2,568)$ \\
\hline RE-DEEM ${ }^{32}$ & $61.8(11.4)$ & 75.9 & $37.6(699 / 1,860)$ & $29.7(5,552 / 1,860)$ & $32.3(600 / 1,886)$ & $67.8(1,261 / 1,860)$ \\
\hline
\end{tabular}

Note: Demographic data were collected for randomized or safety set, as available.

Abbreviations: AF, atrial fibrillation; CAD, coronary artery disease; MI, myocardial infarction; NA, no available data; SD, standard deviation; TKR, total knee replacement; VTE, venous thromboembolism; BISTRO, Boehringer Ingelheim Study in Thrombosis; PETRO, Dabigatran with or without concomitant aspirin compared with warfarin alone in patients with nonvalvular atrial fibrillation; RE-DEEM, RandomizEd Dabigatran Etexilate Dose Finding Study in Patients With Acute Coronary Syndromes Post Index Event With Additional Risk Factors for Cardiovascular Complications Also Receiving Aspirin and Clopidogrel: Multicentre, Prospective, Placebo Controlled, Cohort Dose Escalation Study; RE-LY, RandomizedEvaluation ofLong-termanticoagulation therapY;RE-COVER,ARandomizedTrial ofDabigatran Versus Warfarin in the Treatment ofAcuteVenous Thromboembolism; RE-MODEL, Regulation of Coagulation in Orthopedic surgery to $p$ Revent Deep venous thrombosis and pulmonary embolism; RE-NOVATE, Oral dabigatran versus enoxaparin for thromboprophylaxis after primary total hip arthroplasty; RE-MOBILIZE, prevention of venous thromboembolism after total knee arthroplasty trial; Re-MEDY, A Phase III, Randomised, Multicenter, Double-blind, Parallel-group, Active Controlled Study to Evaluate the Efficacy and Safety of Oral Dabigatran Etexilate (I50 mg Bid) Compared to Warfarin (INR 2.0-3.0) for the Secondary Prevention of Venous Thromboembolism; RE-SONATE, Twice-daily Oral Direct Thrombin Inhibitor Dabigatran Etexilate in the Long Term Prevention of Recurrent Symptomatic VTE. 
Table S2 Definition of MI/ACS events

\begin{tabular}{|c|c|}
\hline Trial & Definition of MI/ACS events \\
\hline BISTRO $\|^{20}$ & Events were selected as AEs according to sub-SMQ MI. Events were not adjudicated \\
\hline \multirow[t]{2}{*}{ RE-MODEL ${ }^{21}$} & Events were labeled as MI or reinfarction based on cardiac enzyme or ECG evidence in the blinded medical record \\
\hline & ACS adjudication using MedDRA lower-level terms \\
\hline RE-NOVATE ${ }^{22}$ & $\begin{array}{l}\text { Events were labeled as MI or reinfarction based on cardiac enzyme or ECG evidence in the blinded medical record } \\
\text { ACS adjudication using MedDRA lower-level terms }\end{array}$ \\
\hline RE-MOBILIZE ${ }^{23}$ & $\begin{array}{l}\text { Events were labeled as MI or reinfarction based on cardiac enzyme or ECG evidence in the blinded medical record } \\
\text { ACS adjudication using MedDRA lower-level terms }\end{array}$ \\
\hline Japanese TKR ${ }^{24}$ & $\begin{array}{l}\text { Events were selected as AEs according to sub-SMQ MI } \\
\text { Events were not adjudicated }\end{array}$ \\
\hline RE-NOVATE $\|^{25}$ & Events were labeled as $\mathrm{MI}$ or reinfarction based on cardiac enzyme or ECG evidence in the blinded medical record \\
\hline PETRO $^{26}$ & Events were prespecified outcome events, but were not adjudicated \\
\hline Japanese $\mathrm{AF}^{27}$ & Events were prespecified outcome events, but were not adjudicated \\
\hline RE-LY',2 & $\begin{array}{l}\text { Events were adjudicated in a blinded manner } \\
\text { Clinical MI was defined as the presence of at least two of the following three criteria: } \\
\text { - Typical prolonged severe chest pain or related symptoms or signs (eg, ST changes or T-wave inversion in the ECG) } \\
\text { suggestive of MI } \\
\text { - Elevation of troponin or creatine kinase-MB to more than the upper level of normal, or if creatine kinase-MB was } \\
\text { elevated at baseline, re-evaluation to }>50 \% \text { increase above the previous level } \\
\text { - Development of significant } Q \text { waves in at least two adjacent ECG leads }\end{array}$ \\
\hline RE-MEDY ${ }^{28}$ & $\begin{array}{l}\text { Investigators identified possible ACS events that were then prospectively adjudicated by an independent committee. } \\
\text { Adjudicated events were then categorized as definite, likely, unlikely, or not ACS }\end{array}$ \\
\hline RE-SONATE ${ }^{29}$ & $\begin{array}{l}\text { Investigators identified possible ACS events that were then prospectively adjudicated by an independent committee. } \\
\text { Adjudicated events were then categorized as definite, likely, unlikely, or not ACS }\end{array}$ \\
\hline RE-COVER ${ }^{30}$ & $\begin{array}{l}\text { Investigators identified possible ACS events that were then prospectively adjudicated by an independent committee. } \\
\text { Adjudicated events were then categorized as definite, likely, unlikely, or not ACS }\end{array}$ \\
\hline RE-COVER III & $\begin{array}{l}\text { Investigators identified possible ACS events that were then prospectively adjudicated by an independent committee. } \\
\text { Adjudicated events were then categorized as definite, likely, unlikely, or not ACS }\end{array}$ \\
\hline RE-DEEM ${ }^{32}$ & $\begin{array}{l}\text { ACS events were prespecified as adverse events of special interest, and included MI, CV death, vascular death, and } \\
\text { unstable angina }\end{array}$ \\
\hline \multicolumn{2}{|c|}{$\begin{array}{l}\text { Abbreviations: ACS, acute coronary syndrome; AE, adverse event; AF, atrial fibrillation; CV, cardiovascular; ECG, echocardiogram; MedDRA, Medical Dictionary for } \\
\text { Regulatory Authorities; MI, myocardial infarction; SMQ, standardized MedDRA query; TKR, total knee replacement; VTE, venous thromboembolism; BISTRO, Boehringer } \\
\text { Ingelheim Study in Thrombosis; PETRO, Dabigatran with or without concomitant aspirin compared with warfarin alone in patients with nonvalvular atrial fibrillation; RE- } \\
\text { DEEM, RandomizEd Dabigatran Etexilate Dose Finding Study in Patients With Acute Coronary Syndromes Post Index Event With Additional Risk Factors for Cardiovascular } \\
\text { Complications Also Receiving Aspirin and Clopidogrel: Multicentre, Prospective, Placebo Controlled, Cohort Dose Escalation Study; RE-LY, Randomized Evaluation of } \\
\text { Long-term anticoagulation therapY; RE-COVER, A Randomized Trial of Dabigatran Versus Warfarin in the Treatment of Acute Venous Thromboembolism; RE-MODEL, } \\
\text { Regulation of Coagulation in Orthopedic surgery to pRevent Deep venous thrombosis and pulmonary embolism; RE-NOVATE, Oral dabigatran versus enoxaparin for } \\
\text { thromboprophylaxis after primary total hip arthroplasty; RE-MOBILIZE, prevention of venous thromboembolism after total knee arthroplasty trial; Re-MEDY, A Phase III, } \\
\text { Randomised, Multicenter, Double-blind, Parallel-group, Active Controlled Study to Evaluate the Efficacy and Safety of Oral Dabigatran Etexilate (I50 mg Bid) Compared to } \\
\text { Warfarin (INR 2.0-3.0) for the Secondary Prevention of Venous Thromboembolism; RE-SONATE, Twice-daily Oral Direct Thrombin Inhibitor Dabigatran Etexilate in the } \\
\text { Long Term Prevention of Recurrent Symptomatic VTE. }\end{array}$} \\
\hline
\end{tabular}

Table S3 Clinical endpoints in RE-DEEM ${ }^{32}$ patients

\begin{tabular}{|c|c|c|c|c|c|}
\hline & \multirow{2}{*}{$\begin{array}{l}\text { Placebo } \\
(n=37 I)\end{array}$} & \multicolumn{4}{|c|}{ Dabigatran } \\
\hline & & $\begin{array}{l}50 \mathrm{mg} \text { bid } \\
(\mathrm{n}=369)\end{array}$ & $\begin{array}{l}75 \mathrm{mg} \text { bid } \\
(\mathrm{n}=368)\end{array}$ & $\begin{array}{l}\text { II } 10 \mathrm{mg} \text { bid } \\
(\mathrm{n}=406)\end{array}$ & $\begin{array}{l}150 \mathrm{mg} \text { bid } \\
(\mathrm{n}=348)\end{array}$ \\
\hline All death, $n(\%)$ & $14(3.8)$ & $8(2.2)$ & $10(2.7)$ & $7(1.7)$ & $7(2.0)$ \\
\hline CV death, $\mathrm{n}(\%)$ & $9(2.4)$ & $8(2.2)$ & $9(2.5)$ & $5(1.2)$ & $4(1.2)$ \\
\hline All MI, n (\%) & $6(1.6)$ & II (3.0) & $10(2.7)$ & $7(1.7)$ & $8(2.3)$ \\
\hline Fatal MI, n (\%) & $2(0.5)$ & $2(0.5)$ & $2(0.5)$ & $0(0.0)$ & $0(0.0)$ \\
\hline Nonfatal MI, n (\%) & $4(1.1)$ & $9(2.4)$ & $8(2.2)$ & $7(1.7)$ & $8(2.3)$ \\
\hline Stroke, n (\%) & $3(0.8)$ & $0(0.0)$ & $\mathrm{I}(0.3)$ & $0(0.0)$ & $0(0.0)$ \\
\hline
\end{tabular}

Note: Part of this table is adapted from Oldgren J, Budaj A, Granger CB, et al. Dabigatran versus placebo in patients with acute coronary syndromes on dual antiplatelet therapy: a randomized, double-blind, phase II trial. Eur Heart J. 20I I;32(22):278I-2789, ${ }^{32}$ by permission of Oxford University Press and the European Society of Cardiology. Copyright $\odot 2011$.

Abbreviations: bid, twice daily; CV, cardiovascular; MI, myocardial infarction; RE-DEEM, RandomizEd Dabigatran Etexilate Dose Finding Study in Patients With Acute Coronary Syndromes Post Index Event With Additional Risk Factors for Cardiovascular Complications Also Receiving Aspirin and Clopidogrel: Multicentre, Prospective, Placebo Controlled, Cohort Dose Escalation Study. 
Vascular Health and Risk Management

Dovepress

\section{Publish your work in this journal}

Vascular Health and Risk Management is an international, peerreviewed journal of therapeutics and risk management, focusing on concise rapid reporting of clinical studies on the processes involved in the maintenance of vascular health; the monitoring, prevention and treatment of vascular disease and its sequelae; and the involvement of metabolic disorders, particularly diabetes. This journal is indexed on PubMed Central and MedLine. The manuscript management system is completely online and includes a very quick and fair peer-review system, which is all easy to use. Visit http://www.dovepress.com/ testimonials.php to read real quotes from published authors.

Submit your manuscript here: http://www.dovepress.com/vascular-health-and-risk-management-journal 